\title{
Teach a Student to Fish? International Relations Scholars in the Classroom
}

\author{
Nina Srinivasan Rathbun, University of Southern California \\ Brian C. Rathbun, University of Southern California
}

ABSTRACT American higher-education institutions are under increasing pressure to prepare their students with practical skills for the workplace, and the social sciences-including political science-are not immune. Political figures have suggested-sometimes seconded by academics themselves-that research distracts academics from imparting practical skills to undergraduate students. Using a survey of international relations (IR) scholars, this article shows that this is not the case. Those who spend more time on research actually devote more time to policy-relevant research in their courses than more abstract and theoretical work, and they incorporate more contemporary issues. Research seems to encourage academics to teach their students to fish.

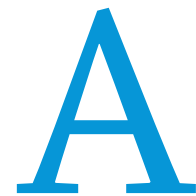

merican institutions of higher education have recently come under close scrutiny, challenged by politicians to gear the educational experience of undergraduates less toward the pursuit of knowledge for its own sake and more toward the development of skills necessary for a twenty-first-century workforce. Most prominent, Wisconsin Governor Scott Walker proposed (although subsequently retracted) a redrafting of the University of Wisconsin's mission statement, removing references to "public service" and "the search for truth" and replacing them with a reference to meeting "the state's workforce needs." The implication is that what most professors do in the classroom does not impart practical skills. Walker also argued that professors should be "teaching more classes and doing more work" (McCalmont 2015). The statement indicates a belief that research distracts from a university's pedagogical mission. This controversy is not confined to Wisconsin. The National Governors Association issued a report in 2011 entitled "Degrees for What Jobs? Raising Expectations for Universities and Colleges in a Global Economy" (Delany 2013).

Academic disciplines that cannot demonstrate this ability seem to be "under the microscope," particularly those that do not fall under the rubric of STEM (i.e., science, technology, engineering, and mathematics). There is increasing interest in connecting state funding for higher education to employment. The National Conference of State Legislators noted that at least 15 states provide monetary incentives for students majoring in "high-demand degrees" (Cohen 2016). Florida Governor Rick Scott recently

Nina Srinivasan Rathbun is associate professor (teaching) in the School of International Relations at the University of Southern California. She can be reached at nrathbun@usc.edu. Brian C. Rathbun is associate professor in the School of International Relations at the University of Southern California. He can be reached at brathbun@usc.edu. convened a task force recommending that students majoring in liberal arts and social sciences pay higher tuition fees because these were "nonstrategic disciplines" (Wong 2015). Kentucky Governor Matt Bevin recently suggested that French majors should not receive state funding (Cohen 2016). Students have also been voting with their feet. There is new interest in practical fields of study for undergraduate students, particularly since the economic recession of 2007-2008 (Flaherty 2015; Hayward 2015).

Therefore, the practical skills that our undergraduates acquire are not solely an academic question (pun intended); the future of the discipline also is involved. There apparently is an impression that we are not teaching students to fish. This article systematically addresses this issue within our own discipline by asking which factors and attributes explain who is more or less likely to emphasize practical teaching in the classroom. It presents evidence from a survey of international relations (IR) academics. The critique that IR scholarship and teaching are impractical has been particularly marked. Nye (2009) took IR scholars to task for "teaching theory and methods that are relevant to other academics but not to the majority of the students sitting in the classroom before them." Goldgeier (2012) specifically praised universities with master's degree programs in the Association of Professional Schools of International Affairs for providing a more multidisciplinary and policy-centered focus.

Our results show that a greater focus on research on the part of professors does not detract from practical teaching-defined in terms of a more contemporary focus and an interest in policyrelevant questions-even as we control for the policy interest of respondents. In fact, research is positively associated. Of course, we cannot establish a causal relationship, but the concern-that scholars are fixated on overly theoretical or esoteric topics in their research, thereby undercutting the future utility of an undergraduate degree-is unwarranted. Indeed, how much time one devotes 
to research is a better predictor of classroom behavior than how much time one commits to teaching.

We first should stress that we remain agnostic about what is best for students. Our aim is to establish the existing pedagogical terrain; we do not advance a normative argument. It is not necessarily better that students learn practical rather than theoretical knowledge. In fact, it might be that theoretical learning is the most practical skill for students because it is a precondition for critical thinking (Guzzini 2001). Readers can form their own judgment about the
In other words, it is considered the least practical of the subfields (Lake 2011). If research activity is associated with greater practicality in teaching IR, this is a particularly strong finding given (in some views) the overly theoretical nature of IR research. The TRIP organizers also defined IR courses in an extremely broad manner-that is, as examining any cross-border process. Immigration, for instance, falls under this definition. As a result, many comparative-politics scholars are included, which constitutes a more representative sample of the discipline than we might suspect.

\section{Of course, we cannot establish a causal relationship, but the concern-that scholars are fixated on overly theoretical or esoteric topics in their research, thereby undercutting the future utility of an undergraduate degree-is unwarranted.}

implications of the findings. We believe we can demonstrate, however, that research activity by faculty members is positively associated with the type of practical learning espoused as necessary in the public debate and increasingly important in today's economy.

\section{DO WE TEACH THE CHILDREN WELL? ANALYZING THE TEACHING PRACTICES OF IR SCHOLARS THROUGH THE 2011 TRIP SURVEY}

We evaluated these questions using the most recent 2011 Teaching, Research and International Policy (TRIP) survey, in which more than 3,00o academics in multiple countries reported not only how and what they research but also what they do in the classroom. The survey was designed and administered by scholars at the Institute for the Theory and Practice of International Relations at the College of William and Mary. The advantages of using the TRIP survey include the size of and variation in the sample. It offers a unique and systematic review of the teaching practices of IR scholars from diverse backgrounds, localities, and substantive approaches. However, given that we are interested in speaking to a largely American debate, we limit this analysis to US-based respondents. The survey organizers compiled comprehensive lists of all faculties in 20 countries that conduct IR research or teach IR courses and other topics that involve cross-border interactions. They then were solicited via e-mail to participate in an online survey asking about their teaching, research, and advocacy. Those contacted at American institutions had a response rate of $42 \%$. We believe that the large sample size compensates for the primary disadvantage-that is, the survey instrument was not designed specifically for our research question. The data have been used extensively to analyze the policy relevance of academics' research (Hundley, Kenzer, and Peterson 2013); the influence of policy-making exposure on their research (Parks and Stern 2013); how political ideology affects adherence to different theoretical perspectives (Rathbun 2012); and the overall tendencies in IR in theory, method, and epistemology (Maliniak, Oakes, Peterson, and Tierney 2011). As of yet, however, the dataset has not been used to explore the teaching of IR scholars.

An ideal survey would encompass all of the political science subfields. Nevertheless, the TRIP survey is extremely useful because it presents a valid case for the practical usefulness of political science. IR is frequently bemoaned as the least policy relevant of the subdisciplines, fixated as it is on theoretical and epistemological questions at the expense of area- or issue-specific knowledge.
This analysis focuses on two questions that capture the practicality of IR teaching: (1) time devoted to policy analysis and/or policy-relevant research; and (2) time devoted to contemporary issues. Those surveyed were asked the percentage of their course time devoted to policy analysis and/or policyrelevant research. As shown in table 1, the modal and the median response was $11 \%$ to $25 \%$, with more than a third of respondents giving this answer. More than $40 \%$ reported devoting more than $25 \%$ of their course time to policy questions; about a fourth of the sample devoted less than $25 \%$. Interest in contemporary IR empirical issues was stronger, with about a quarter of respondents reporting that they devote more than $50 \%$ of their introductory class time to events occurring after 2000.

\section{Table 1 \\ What Do Professors Do in the Classroom?}

Approximately what percentage of your undergraduate Intro to IR course is devoted to policy analysis and/or policy-relevant research? The policies analyzed need not be current

\begin{tabular}{ccc}
\hline & Response & Percentage of sample \\
\hline $0-10 \%$ & $22.7 \%$ \\
\hline $11-25 \%$ & $35.5 \%$ \\
\hline $26-50 \%$ & $27.6 \%$ \\
\hline $51-75 \%$ & $11.0 \%$ \\
\hline $76-100 \%$ & $3.2 \%$ \\
\hline$N=895$ & \\
\hline
\end{tabular}

Approximately what percentage of your undergraduate Intro to IR course is devoted to contemporary empirical issues in IR - i.e., 2000 or later?

\begin{tabular}{ccc}
\hline & Response & Percentage of sample \\
\hline $0-10 \%$ & $14.5 \%$ \\
\hline $11-25 \%$ & $30.0 \%$ \\
\hline $26-50 \%$ & $28.9 \%$ \\
\hline $51-75 \%$ & $21.9 \%$ \\
\hline $76-100 \%$ & $4.6 \%$ \\
\hline $\mathrm{N}=889$ & \\
\hline
\end{tabular}


The median category was $26 \%$ to $50 \%$, meaning that more than half of respondents devote $25 \%$ or more of class time to contemporary topics.

Our interest is less in the distribution of responses than the determinants of individual-level differences among academics. Who is more or less likely to discuss policy-relevant research and contemporary issues in their courses? We identified several potentially important factors and attributes. Most important is the way that academics devote their time as measured in the TRIP pure theory) should be considered-was overwhelmingly qualitative research.

We imagine that those who identify with paradigms are less interested in practical teaching because their research focus may be more oriented toward answering large theoretical questions about the nature of IR-answers that may span large swaths of time-than solving discrete, policy-relevant questions (e.g., how to improve human rights today). This is Lake's critique; he complains that "We...organize courses-and especially introductory courses

\section{Who is more or less likely to discuss policy-relevant research and contemporary issues in their courses? We identified several potentially important factors and attributes. Most important is the way that academics devote their time as measured in the TRIP survey in ordinal fashion.}

survey in ordinal fashion. The primary hypothesis concerns the relative teaching-research balance of faculty and how it influences the practicality of their teaching. Considering the state of the public debate reviewed previously, the conventional wisdom is that:

The more time that academics devote to research, the less practical their teaching will be, captured in terms of attention paid to contemporary and policy-relevant issues.

We must control for other variables that also might influence the practicality of teaching. Those who decry the lack of policy relevance in IR scholarship might expect that faculty at institutions with doctoral programs or those who devote more time to research will be less practical because they teach what they know: the inaccessible, theoretically informed, jargon-loaded state of IR research (Jentleson 2002; Nye 2009; Walt 2005). Conversely, liberal-arts colleges-and, indeed, liberal-arts education itself-have been criticized frequently for their refusal to focus on developing students' practical skills (Delany 2013). We created dichotomous variables to evaluate three types of institutions. Although there was no question that asked respondents at which type of institution they teach they were asked if in the last five years they taught only undergraduates or any $\mathrm{PhD}$ students. We created three categories-undergraduate only, institutions with $\mathrm{PhD}$ programs and everything else (most likely programs with masters' programs but no $\mathrm{PhD}$ program).

We controlled for the policy interest of respondents, creating a dummy variable for those who reported that policy relevance is the most important factor driving their research. They may be more naturally inclined toward teaching about contemporary policy issues. Methodology and epistemology may also find their way into the classroom. Those who use methods that require intense technical training (e.g., formal theory and quantitative methods) also may be less likely to orient their classes in a practical direction. As discussed previously, many critics who decry the lack of policy-relevant research useful to the policy community locate the problem in methodological trends in the discipline. We used different dummy variables based on questions that asked respondents to identify their primary research methodology. The main excluded category-against which the effect of the dummies (which also included policy analysis and and graduate field seminars-in terms of the 'great debates' or 'great books' where we assign exemplary works that help students identify the core traits of each tradition" $(2011,467)$. As an alternative, he recommended more practical teaching, oriented toward problem-solving (ibid., 471). TRIP respondents were asked to respond with which, if any, paradigm they identified. We created a dummy variable to categorize whether or not individuals were paradigmatic.

There is a vast and vibrant literature on gender differences in teaching. Studies have found gendered differences in teaching methods-regardless of field-with women favoring a more interactive, learner-centered style. A few studies found gendered differences in communication styles, with female professors tending to generate more class discussion, more interaction, and more give-and-take than male professors (Statham, Richardson, and Cook 1991). Women tend to value student interaction, voice more concern about students' self-esteem, and appreciate collaboration with colleagues to improve teaching more than men, regardless of field (Goodwin and Stevens 1993). All of these findings suggest that women tend to focus more on the student as the locus of learning, whereas men focus more on imparting their own knowledge. This leads to an expectation that women will be more practical in their teaching, which corresponds with a greater practical policy interest in female IR scholars' research. Maliniak et al. $(2008,136)$ found that a slightly higher percentage of women state that they have an immediate policy application in mind when conducting their research.

We also considered the effect of age. Unsurprisingly, Maliniak et al. (2008) found that younger researchers are less interested in policy. Similarly, they found that scholars who have recently completed graduate training tend to focus more on academic debates in their teaching and less on preparing their "students to become informed participants in debates about foreign policy and international politics" (Maliniak et al. 2008, 141).

\section{RESULTS}

\section{Practical Teaching}

Table 2 presents the results of a set of ordered logit models. Two dependent variables capture how survey respondents organize and teach their introductory IR course for undergraduatesthat is, how policy relevant and contemporary their focus is. The dependent variable has five categories that correspond to the 
Table 2

\section{Determinants of Practical Teaching}

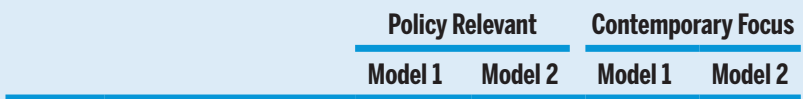

\section{Type of Students}

\begin{tabular}{|c|c|c|c|c|}
\hline PhD Students & -0.33 & $-0.59^{*}$ & -0.07 & -0.33 \\
\hline & $(0.21)$ & $(0.26)$ & $(0.20)$ & $(0.26)$ \\
\hline \multirow[t]{2}{*}{ Only Undergraduates } & -0.26 & $-0.53^{*}$ & -0.03 & $-0.36 \#$ \\
\hline & $(0.17)$ & $(0.23)$ & $(0.17)$ & $(0.22)$ \\
\hline \multicolumn{5}{|l|}{ Teaching Commitments } \\
\hline \multirow[t]{2}{*}{$11 \%-25 \%$} & 0.36 & 0.93\# & $-0.78 \#$ & $-1.35^{*}$ \\
\hline & $(0.46)$ & $(0.55)$ & $(0.45)$ & $(0.54)$ \\
\hline \multirow[t]{2}{*}{$26 \%-50 \%$} & 0.14 & 0.53 & $-0.86^{*}$ & $-1.52^{* *}$ \\
\hline & $(0.44)$ & $(0.53)$ & $(0.44)$ & $(0.53)$ \\
\hline \multirow[t]{2}{*}{$51 \%-75 \%$} & 0.18 & 0.64 & -0.47 & $-1.17^{*}$ \\
\hline & $(0.44)$ & $(0.53)$ & $(0.43)$ & $(0.53)$ \\
\hline \multirow[t]{2}{*}{$76 \%-100 \%$} & 0.45 & 0.91 & -0.18 & -0.78 \\
\hline & $(0.50)$ & $(0.58)$ & $(0.49)$ & $(0.58)$ \\
\hline
\end{tabular}

Research Commitments

\begin{tabular}{|c|c|c|c|c|}
\hline \multirow[t]{2}{*}{$11 \%-25 \%$} & $0.54^{* *}$ & $0.52^{*}$ & 0.33\# & $0.47^{*}$ \\
\hline & $(0.19)$ & $(0.23)$ & $(0.20)$ & $(0.24)$ \\
\hline \multirow[t]{2}{*}{$26 \%-50 \%$} & $0.68^{* * *}$ & $0.75^{* *}$ & $0.90 * * *$ & $1.04^{* * *}$ \\
\hline & $(0.21)$ & $(0.25)$ & $(0.21)$ & $(0.25)$ \\
\hline \multirow[t]{2}{*}{$51 \%-75 \%$} & $0.85^{* * *}$ & $0.85^{* *}$ & $1.16^{* * *}$ & $1.09^{* * *}$ \\
\hline & $(0.26)$ & $(0.31)$ & $(0.26)$ & $(0.31)$ \\
\hline \multirow[t]{2}{*}{$76 \%-100 \%$} & 0.40 & $1.01 \#$ & 0.76 & 0.92\# \\
\hline & $(0.47)$ & $(0.57)$ & $(0.47)$ & $(0.55)$ \\
\hline \multirow[t]{2}{*}{ Policy-Motivated Research } & $0.74^{* * *}$ & $0.69 * * *$ & 0.10 & 0.06 \\
\hline & $(0.14)$ & $(0.17)$ & $(0.14)$ & $(0.16)$ \\
\hline \multirow[t]{2}{*}{ Paradigmatic Adherence } & -0.24 & -0.28 & -0.20 & -0.17 \\
\hline & $(0.16)$ & $(0.19)$ & $(0.16)$ & $(0.19)$ \\
\hline \multicolumn{5}{|l|}{ Primary Methodology } \\
\hline \multirow[t]{2}{*}{ Quantitative } & $-0.35^{*}$ & -0.32 & $-0.35^{*}$ & $-0.37 \#$ \\
\hline & $(0.17)$ & $(0.20)$ & $(0.17)$ & $(0.20)$ \\
\hline \multirow[t]{2}{*}{ Formal } & -0.54 & -0.44 & -0.02 & -0.20 \\
\hline & $(0.52)$ & $(0.59)$ & $(0.52)$ & $(0.60)$ \\
\hline \multirow[t]{2}{*}{ Pure Theory } & $-0.89 \#$ & -0.74 & -0.66 & -0.44 \\
\hline & $(0.51)$ & $(0.56)$ & $(0.57)$ & $(0.62)$ \\
\hline \multirow[t]{2}{*}{ Policy Analysis } & 0.35 & 0.54 & 0.30 & 0.42 \\
\hline & $(0.23)$ & $(0.29)$ & $(0.22)$ & $(0.28)$ \\
\hline \multicolumn{5}{|l|}{ Epistemology } \\
\hline \multirow[t]{2}{*}{ Non-Positivist } & -0.02 & 0.08 & -0.01 & -0.02 \\
\hline & $(0.17)$ & $(0.21)$ & $(0.17)$ & $(0.21)$ \\
\hline \multirow[t]{2}{*}{ Post-Positivist } & -0.08 & -0.08 & 0 & -0.10 \\
\hline & $(0.17)$ & $(0.21)$ & $(0.17)$ & $(0.20)$ \\
\hline
\end{tabular}

(continued)
Table 2 (Continued)

\begin{tabular}{|c|c|c|c|c|}
\hline & \multicolumn{2}{|c|}{ Policy Relevant } & \multicolumn{2}{|c|}{ Contemporary Focus } \\
\hline & Model 1 & Model 2 & Model 1 & Model 2 \\
\hline \multicolumn{5}{|l|}{ Age } \\
\hline \multirow[t]{2}{*}{$20-34$} & & $-0.54^{*}$ & & -0.03 \\
\hline & & $(0.25)$ & & $(0.25)$ \\
\hline \multirow[t]{2}{*}{$35-44$} & & -0.23 & & 0.20 \\
\hline & & $(0.19)$ & & $(0.19)$ \\
\hline \multirow[t]{2}{*}{55 and older } & & -0.26 & & -0.22 \\
\hline & & $(0.20)$ & & $(0.20)$ \\
\hline \multirow[t]{2}{*}{ Female } & & $0.33^{*}$ & & $0.71^{* * *}$ \\
\hline & & $(0.17)$ & & $(0.17)$ \\
\hline Cut 1 & -0.83 & -0.74 & -2.10 & -2.83 \\
\hline Cut 2 & 0.80 & 0.88 & -0.49 & -1.12 \\
\hline Cut 3 & 2.33 & 2.51 & 0.81 & 0.22 \\
\hline Cut 4 & 4.03 & 4.13 & 2.87 & 2.38 \\
\hline Pseudo R2 & 0.03 & 0.04 & 0.02 & 0.03 \\
\hline Chi2 & 64.10 & 59.70 & 37.66 & 59.27 \\
\hline $\mathrm{N}$ & 841 & 612 & 837 & 609 \\
\hline
\end{tabular}

Notes: Table entries are ordered logit coefficients with standard errors in parentheses. ${ }^{* * *} p<0.001 ;{ }^{* *} p<0.01 ;{ }^{*} p<0.05 ; \# p<0.10$. All variables are dichotomous. The excluded category for epistemology is positivism; for age, it is 35-45; and for teaching and research commitments, it is $0 \%-10 \%$.

results presented in table 1 . For each dependent variable, the first model excludes the demographic factors of gender and age. A substantial number of respondents opted not to report this information; therefore, the sample declines from slightly less than 900 to slightly more than 600 for the full models. A number of findings stand out, as listed in the following discussion.

\section{Devoting significant time to research is associated with greater attention to policy issues and more contemporary events in respondents' introductory IR courses}

In other words, we reject the main hypothesis implicated in the public debate. It is actually those who spend more time researching that have a greater practical orientation in their undergraduate classrooms. This model controls for respondents' self-reported motivation to inform policy questions in one's research as well as one's teaching commitments and the type of institution where one works; thus, it is not a simple function of teaching what one researches. Research, therefore, may be beneficial for inspiring practical teaching, although we cannot know definitively the direction of the causal relationship. It is obvious that we cannot comment on whether students in these classes benefit from this focus or emerge with actual skills that others do not acquire. It depends on the performance of the professor and whether policy learning is actually better at imparting practical skills, on which we remain agnostic. However, it is clear that the students are more exposed to certain types of questions.

Figure 1 presents the predicted probabilities of devoting a particular percentage of a course to policy questions for the following three categories of respondents: those who spend $0 \%$ to $10 \%$ (least research active), $26 \%$ to $50 \%$ (moderate research active), and $76 \%$ 
to $100 \%$ (most research active) of their time on research. For each type, there are five estimates: the probability that they will devote o\% to $10 \%, 11 \%$ to $25 \%, 26 \%$ to $50 \%, 51 \%$ to $75 \%$, and $76 \%$ to $100 \%$ of their course time to policy questions. The lines connecting these points are not based on specific point estimates but rather are intended to show the general trend across the categories.

Figure 1 shows that those who are the least research active have a greater likelihood (41\%) of devoting only o\% to $10 \%$ of their course time to policy questions. This likelihood drops to $25 \%$ for moderately research active and $21 \%$ for most active research scholars. Most research active and moderately research active scholars are significantly more likely than least active researchers type to spend $26 \%$ to $50 \%$ or even $51 \%$ to $75 \%$ of their course time on contemporary issues. Again, we see that few scholars spend $76 \%$ to $100 \%$ on contemporary questions, regardless of research activity.

\section{The amount of time spent on research is a more consistent predictor of practicality in teaching than the amount spent on teaching}

Teaching commitments have an effect (albeit weak) on how much an instructor integrates contemporary issues into courses but not on how policy relevant the course is. The effect of greater time committed to teaching is actually negatively associated with

\section{It is actually those who spend more time researching that have a greater practical orientation in their undergraduate classrooms.}

to spend $26 \%$ to $50 \%$ of their course time on policy-relevant classes (i.e., $30 \%$ and $27 \%$ compared to $17 \%$, respectively). Beginning with $11 \%$ to $25 \%$, there is a general downward slope in probabilities for all types because, in general, fewer scholars spend this much time on policy questions.

Figure 2 shows a similar trend for devoting course time to contemporary issues. Those who do little research are roughly twice as likely to spend only $0 \%$ to $10 \%$ of their course time on contemporary issues as those with moderate or most active research commitments (i.e., $31 \%$ likelihood as opposed to $14 \%$ and $17 \%$, respectively). The latter two types are more likely than the former

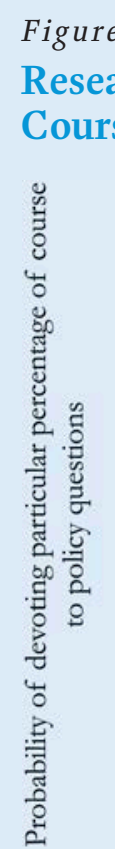

a dedication to understanding current events. Those with a greater teaching commitment seem to have a more historical focus. Therefore, teaching style demonstrates a greater association with how much more time is devoted to research than teaching!

At the same time, we also observed that those who teach $\mathrm{PhD}$ students at their institution devote slightly less time to policy issues, after controlling for gender and age. The same is true of those who teach only undergraduates. It appears that teaching master's students generates a greater policy focus for respondents even in their undergraduate courses. The type of institution that undergraduates attend-that is, whether their professors simultaneously teach $\mathrm{PhD}$ and master's students-matters to some degree, although the effects are relatively small. This finding seems to support Goldgeier's (2012) argument that practical teaching at the undergraduate level is greater at institutions with master's programs in policy.

\section{Dedication to a particular paradigm does not influence the practicality of one's teaching}

We might expect that those who work within a particular paradigm are interested primarily in theoretical issues and in pushing the boundaries of their preferred research tradition, giving short shrift to practical policy questions and current events. This has been the theme of those concerned about the theory-practice divide in political science and IR. Whereas this might be a genuine concern in terms of research, it does not appear to be the case in teaching. Identification with any paradigm listed, as opposed to actively declining such an affiliation, has no association with 


\section{Figure 2}

\section{Research Activity Is Associated with Greater Focus on Contemporary Issues in IR Courses}

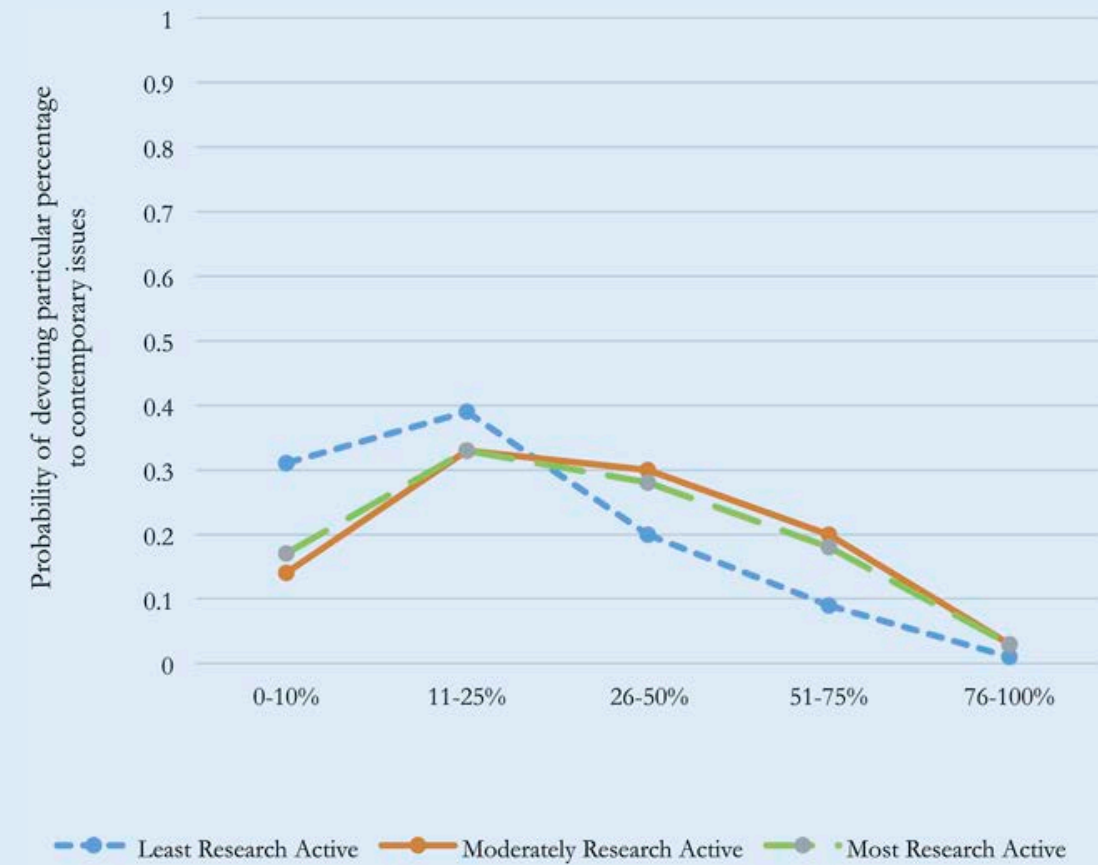

Figure 3

\section{Female Professors Are Much More Likely to Devote More Attention to Contemporary Questions of IR in Their Courses}

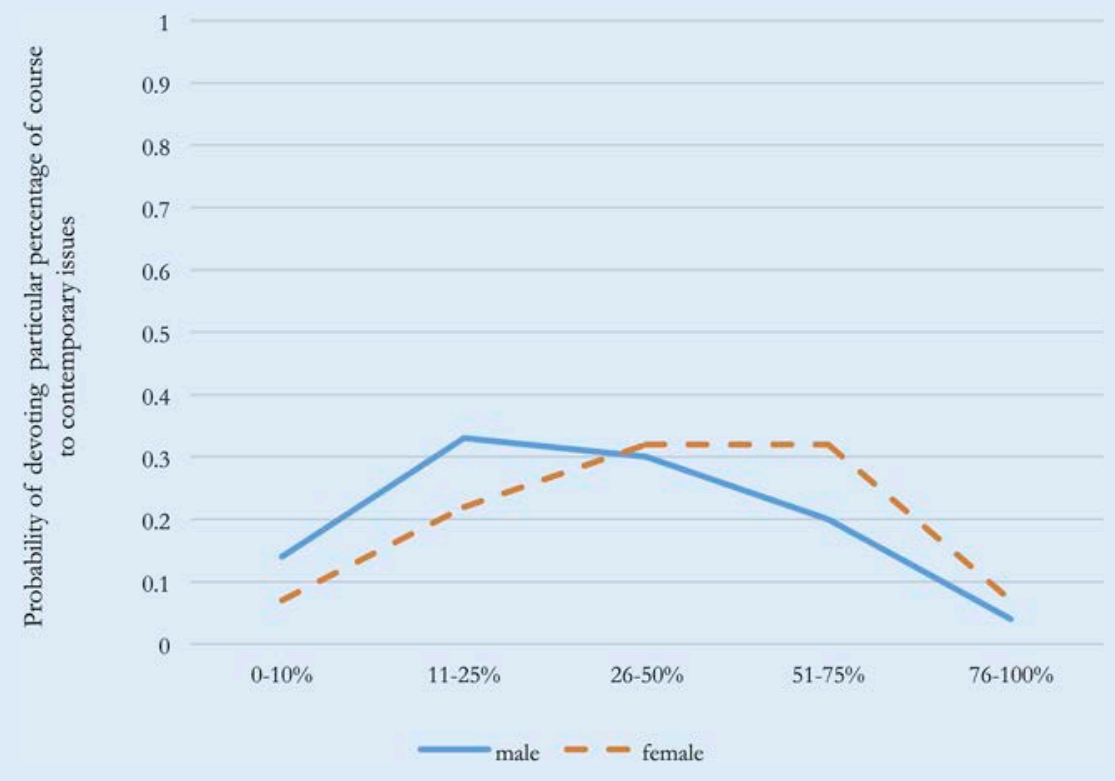

Methodology and epistemology also do not intrude into the practicality of one's teaching

As expected, those who engage in policy analysis as their primary type of research tend to be more policy focused in their teaching; however, this does not appear to be the case after controlling for gender and age. Again, we expect that quantitative scholars, formal modelers, and pure theoreticians may retreat from practical teaching because their research often is lamented as less accessible and less concerned with solving contemporary problems (Kristof 2014; Nye 2009). This is the implication of critiques leveled at IR research, but it does not appear to be the case except for a minor negative effect on quantitative research. We also observed no difference based on respondents' epistemological preferences. Non-positivists and post-positivists exhibit no more or less interest in policy-relevant questions or contemporary issues. Game theorists and poststructuralists are as likely as historically oriented or positivist scholars to spend course time on contemporary problems with policy relevance.

\section{Gender is a consistently important variable in the practicality of one's teaching}

Women are more devoted to making their classes practical. The predicted probability of spending $0 \%$ to $10 \%$ of class time on policy questions for men is $24 \%$; for women, it is $18 \%$. As shown in figure 3 , the effect on the integration of contemporary issues is particularly strong. Women actually are more likely to spend $26 \%$ to $50 \%$ or $51 \%$ to $75 \%$ of their class time on contemporary problems than $0 \%$ to $10 \%$ or $11 \%$ to $25 \%$. Men are about twice as likely to spend only o\% to $10 \%$ as women (i.e., $17 \%$ likelihood as opposed to 9\%) and they trail women by 9 percentage points in the $51 \%$ to $75 \%$ category.

This is, of course, after controlling for a number of other factors that might influence how women-as opposed to men-teach, such as their greater teaching commitments. There is simply something different about women in the classroom, which dovetails with previous research on their greater active-learning commitments. Women appear to be more dedicated to discussing policy issues that confront today's world. either of the dependent variables. Therefore, even the most theoretical of IR academics with the most abstract research interests are not predisposed toward less practical teaching.

\section{TRAINING FISHERMEN}

Those who spend more time on research are more policy focused and engaged with contemporary issues in the classroom, whereas 
one's teaching commitments have less association. Women teach in a more practical manner than men. This suggests that two of the problems facing the academy-that colleges and universities are not adapted to the modern world and the difficulties that women in particular face in balancing career and familyare related. Helping women succeed would also improve the practicality of the political science degree, given their style of teaching. Research activity helps us to teach students to catch fish for themselves.

\section{ACKNOWLEDGMENTS}

The authors are grateful to Michael Tierney and Susan Petersen for providing the TRIP data and for answering all of our questions. We thank the editors and reviewers for their feedback.

\section{REFERENCES}

Cohen, Patricia. 2016. "A Rising Call to Promote STEM Education and Cut Liberal Arts Funding." New York Times, February 21.

Delany, Ella. 2013. "Humanities Studies under Strain around the Globe." New York Times, December 2.

Flaherty, Colleen. 2015. "Rethinking Poli-Sci." Inside Higher Education, May 29. https://www.insidehighered.com/news/2015/05/29/stanford-political-sciencedepartment-overhauls-undergraduate-major

Goldgeier, James. 2012. "Undisciplined: The Ivory Tower Survey Is Asking the Wrong Questions of Wrong People." Foreign Policy (January/February). http:// foreignpolicy.com/2012/01/o3/undisciplined/

Goodwin, Laura D. and Ella A. Stevens. 1993. "The Influence of Gender on University Faculty Members' Perceptions of 'Good' Teaching." The Journal of Higher Education 64 (2): 166-85.
Guzzini, Stefano. 2001. "The Significance and Roles of Teaching Theory in International Relations." Journal of International Relations and Development 4 (2): 98-117.

Hayward, Steven F. 2015. "Is Political Science Dying? Its Wounds Are Self-Inflicted.” The Weekly Standard, December 21.

Hundley, Lindsay, Benjamin Kenzer, and Susan Peterson. 2013. "What Pivot? International Relations Scholarship and the Study of East Asia." International Studies Perspectives 14 (1): 1-16.

Jentleson, Bruce. 2002. "The Need for Praxis: Bringing Policy Relevance Back In." International Security 26 (4): 169-83.

Kristof, Nicholas. 2014. "Professors, We Need You!” New York Times, February 16.

Lake, David A. 2011. "Why 'Isms' Are 16.Evil: Theory, Epistemology, and Academic Sects as Impediments to Understanding and Progress." International Studies Quarterly 55 (2): 465-80.

Maliniak, Daniel, Amy Oakes, Susan Peterson, and Michael J. Tierney. 2008. "Women in International Relations." Politics \& Gender 4 (1): 122-44.

—. 2011. "International Relations in the U.S. Academy." International Studies Quarterly 55 (2): 437-64.

McCalmont, Lucy. 2015. "Scott Walker Urges Professors to Work Harder." Politico, January 29. http://www.politico.com/story/2015/01/scott-walkerhigher-education-university-professors-114716

Nye, Joseph. 2009. "Scholars on the Sidelines." Washington Post, April 13.

Parks, Bradley C. and Alena Stern. 2013. "In-And-Outers and Moonlighters: An Evaluation of the Impact of Policy-Making Exposure on IR Scholarship." International Studies Perspectives 15: 73-93.

Rathbun, Brian. 2012. "Politics and Paradigm Preferences: The Implicit Ideology of International Relations Scholars." International Studies Quarterly 56 (3): 607-22.

Statham, Anne, Laurel Richardson, and Judith Cook. 1991. Gender and University Teaching: A Negotiated Difference. Albany: State University of New York Press.

Walt, Stephen W. 2005. "The Relationship between Theory and Policy in International Relations." Annual Review of Political Science 8: 23-48.

Wong, Alia. 2015. "The Governor Who (Maybe) Tried to Kill Liberal-Arts Education.” The Atlantic, February 11. 